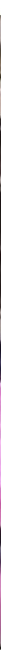

Editors:

Jaime Almansa Sánchez and Elena Papagiannopoulou

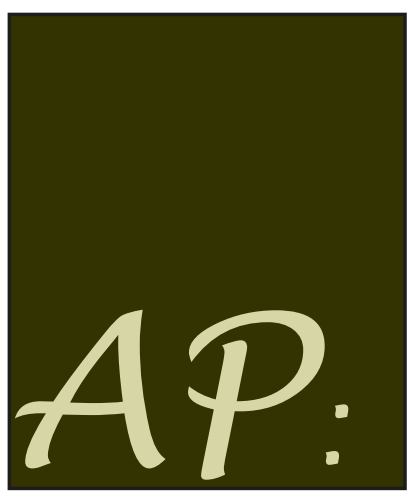

www.arqueologiapublica.es

Ontine Journat in Public Archaeology

AP: Online Journal in Public Archaeology is edited by JAS Arqueología S.L.U. 


\section{INDEX}

Editorial

Jaime Almansa Sánchez and Elena Papagiannopoulou

Mutual Education. Towards a model of educational co-creation around the archaeological heritage of Mexico

Jaime Delgado Rubio

Communicating Cultural Heritage Resources to the Public: Experiences from the Makonde of Mtwara Region, Tanzania

Festo Wachawaseme Gabriel

Reflecting on evaluation in public archaeology

Kate Ellenberger and Lorna-Jane Richardson

Points of You: Historical graffiti and pop culture: A public archaeology perspective

Alberto Polo Romero and Diana Morales Manzanares

Review

Antipatrimonio

Nekbet Corpas Cívicos

Review

Archaeogaming

Daniel García Raso

Review

Yacimiento pixel

Jaime Almansa-Sánchez 
AP: Ontine Journat in Public Archaeology Volume 8 - 2018 p. 65-94

\title{
Reflecting on evaluation in public archaeology
}

\author{
Katharine ELLENBERGER \\ Heritech Consulting \\ Lorna-Jane RICHARDSON \\ University of East Anglia
}

Received: 31/05/2017 - Accepted: 02/10/2018

\section{Abstract}

As heritage professionals, our community-facing projects are embedded in the politics of cultural heritage and reverberate throughout the communities where we work. The only way to know if archaeological outreach and community engagement are working is to ask stakeholders, and there is growing support in our community of practice to further develop this aspect of the field. There is also increasing pressure to use evaluations, particularly standardized impact assessments motivated by neoliberal political critiques, to argue that archaeological projects are legitimate uses of economic resources. As the field continues to develop more robust mechanisms of self-assessment, we urge further reflection on whether our assessment of successful outcomes balances differing expectations and definitions of success, requirements of funding institutions, willingness of the participants, and needs of the practitioners. Are we working towards assessments of our own satisfaction with work done, the satisfaction of the dominant political forms of cultural value, the formal procedures of our funding streams, or the experiential and educational needs of the non-professional with whom we engage? We present a picture of the institutional contexts of US and UK public archaeology evaluation up to this point and propose ways to move forward that address the ethical underpinnings of public archaeology practice while strengthening the institutional visibility of public archaeology work. 
66 - K. ELLENBERGER \& L.-J. RICHARDSON - Reflecting on evaluation...

\section{Keywords}

public archaeology, evaluation, public engagement, communication.

\section{Introduction}

The present era of global financial insecurity has led to significant cuts to public funding for archaeological work across the globe and greater vulnerability for heritage protections in national legislation (Howery 2013; Jackson et al. 2014). There is greater emphasis placed on demonstrable social and economic value of science in modern global politics (Grey 2008; James 2018: Vyck 2010) which places many archaeologists in a position of needing to provide evidence for the value and impact of their work. Assessing how we undertake evaluation and assessment of public archaeology projects is therefore a vital area for promoting and sharing impactful research, despite its underrepresentation as a discreet subject area in published academic work. In the following discussion, we will explore the current state of formal evaluation in public archaeology, from our perspectives working in the USA and the UK. We will discuss the formal evaluation requirements of major funding sources for public archaeology in each of these national contexts and the evaluation processes found there. These range from detailed assessments of learning outcomes to explorations of the impact on well-being and socio-economic profiles to simple collations of visitor numbers and anecdotal comments collected during events and activities. These data are not, as Gould (2016), Neal (2015) and the authors of this paper conclude, robust in their methods of data collection, nor are they representative of the discipline, the participants, or the aspirations of the sector. Additionally, we note several points for consideration that where formal project evaluations have been undertaken, these are often not aggregated nor made publicly available, the requirements of the funding body or similar are open to a range of interpretations by the organisations undertaking the work, or may simply not take place at all. This paper will then suggest some future directions for participatory evaluation, which reflect the values of the communities with whom we work, as well as reflecting our professional standards and responsibilities as archaeologists. 
Public archaeology is critical to the wider discipline. Although there are many definitions of the term 'public archaeology' (Richardson and Almanza-Sanchez 2015; Skeates, McDavid and Carman 2012), any practice in which archaeology and "the public" intersect can qualify (McDavid and Brock 2014, 165). As austerity policies and neoliberal politics have further impacted the already-predominantly marketized archaeological sector, there are increasing demands for public archaeology practitioners to comply with 'policy audit practices to garner legitimacy for demands over the public purse (irrespective of whether they, in fact, promote or muddle issues of transparency, democratic accountability and effectiveness)' (Belfiore 2015, 96). Alongside these concerns, the use of 'impact' metrics to measure the "social, cultural and economic value" of academic work in higher education in the UK and elsewhere have emerged alongside governmental austerity agendas (James 2018, 312). There is a growing pressure for research to demonstrate "the economic and cultural values and impacts of archaeological resources" (Schadla-Hall et al. 2010, 62), but this emphasis may not help us understand our effect on, and improve our work with, stakeholder communities, especially when undertaken within a developer-led archaeological context. It is possible that these neoliberal agendas may reduce community projects to opportunities that impact perceptions of archaeology by local stakeholders and government officials, and in turn, simply further sustain financial support for the subject. Yet many public archaeology projects are undertaken because of a commitment to education, community well-being, and a strong sense of social justice amongst its practitioners - it is considered unethical to exclude stakeholders from research that might impact their perception of their own heritage, their local community, or even their financial situation (Jancovich \& Bianchini 2013: Marshall et al. 2002: Neal 2015).

To date, in the archaeological literature, there is little work published on whether or how scholars might formally evaluate their public engagement practice, and find out whether these activities achieve their organisational aims as well as their social functions. Many sources of funding for community archaeology do not ask for formal evaluation of outcomes and where guidance for evaluation exists, the format and extent of such evaluation appears to be open 
to interpretation. Beyond the imperatives provided by relevant funding bodies to understand indicators of success, which we set out below, there is little guidance from the main archaeological bodies in the UK and USA, on methods to use to measure education, well-being, or social impact outcomes or to evaluate the range and participation in activities (Simpson and Williams 2008). The discussions that do exist in the available guidance on the subject of evaluation and measuring success are invariably positive and embellish what Fredheim $(2018,622)$ identifies as the "exclusively positive discourse of heritage" and this in turn "normalizes certain experiences and thereby silences and excludes others".

\section{National Contexts}

Community archaeology projects often develop networks and communities, and set out to engage groups of people with a specific archaeological subject, site or historic period. It is both common sense, and a necessary budgetary reporting mechanism, to collate data that can measure these engagements, successes, or failures, and facilitate lessons learned within and between organizations. However, as Neal $(2015,135)$ points out, "measuring the impact of interventions on individuals is something that many community archaeology projects attempt, but not in any formalized sense". There is an overall lack of methodology, a heavy reliance on anecdote, and sometimes crude measures for success (Neal and Roskams 2013).

This section examines the contexts within which public engagement and community archaeology work takes place within the USA and UK, and briefly examines the forms of evaluation required by the major funding streams in both countries.

\section{USA}

In the USA, archaeological work takes place in developmentdriven contract archaeology, academic research, and through museums and community organizations. Although we are not aware of any concrete data on the relative prominence of each 
category, it is accepted by most practitioners that Cultural Resource Management (CRM) archaeologists conduct the most archaeological projects (see synthesis in Neumann 2001).

CRM professionals work within private companies, State and Tribal Historic Preservation Offices (known as SHPOs and THPOs), and in government agencies managing public land such as the National Parks Service (NPS) or the Bureau of Land Management (BLM). Archaeologists excavating on public land require a permit, the allocation of which is based on the qualifications of the researcher (and whether the proposed work is consistent with the agency's priorities and management plans, e.g. National Park Service 2016a). Excavations on private land, however, are typically only regulated by legislation protecting specific types of material, and only under certain circumstances. Although there are numerous federal laws, federal policies, state laws, local laws, and other legal structures which govern access to cultural resources, there are very few which mandate routine outreach. A notable exception is the National Strategy for Federal Archeology established in 1990 by the US Department of Interior, and affirmed as official government policy in 1999 (United States Department of the Interior 1999). The strategy document describes how the Department's employees - who manage the Nation's natural and cultural resources and commitments to Indigenous governments - will use volunteer programs and public interpretation activities to increase participation in the nation's archaeology by the general public.

Outside the government in particular, public archaeology in the United States is characteristically diverse and contextually specific. The publications that describe public archaeology projects in the US typically focus on the impetus for the work, but do not describe the methodology employed to fulfill the goals set forth if public engagement was a focus, or they mention public presentations done in addition to the research which is framed as of central importance. In short, public archaeology methods and reflection on their efficacy have not been a focus of scholarly discussion in American public archaeology. This does not mean that work up until this point has not been carefully designed or that colleagues are not assessing their work, but that publishing methods and 
results in scholarly journals does not seem to be understood as the standard intellectual contribution in this scholarly community, so a routine literature review does not capture the richness of what has been done in the field.

Most non-commercial archaeology funding in the USA comes from the federal government, and little of this funding is designed specifically to support public outreach. Major funding sources for archaeologists include federal agencies funding scientific research (National Science Foundation - NSF), humanities and teachers (National Endowment for the Humanities), and private organizations dedicated to developing anthropological theory (e.g. Wenner Gren Foundation, School for Advanced Research), amongst others. While many of these organizations require applicants to explain the intellectual impacts of the proposed work at multiple scales, none explicitly require applicants to assess the public impact of their work. In addition, a 1980 study analyzing how much money the National Science Foundation (NSF) granted for archaeological research found that the amount of funding did not keep up with the growing number of archaeologists (Casteel 1980:171-176). In short, there seems to be less funding than there was for previous generations, and funding institutions appear disinterested in systemically promoting or assessing public outreach.

Changes at the NSF and Wenner-Gren Foundation seem to signal that public perception of archaeology is of greater concern in the past 20 years. In 1995, the NSF overhauled its application format and made it mandatory for applicants to explain the "broader impacts" of their project beyond the discipline (Brenneis 2009:243-244), requiring researchers to re-frame their research to articulate the disciplinary, scientific, and societal impact of knowledge production (NSF 2016). All but one analysis of NSF Archaeology (Cullen 1995; Goldstein et al. 2018; Yellen et al. 1980) and Anthropology (Plattner et al. 1987; Plattner and McIntyre 1991) funding patterns was done before this change took place. ${ }^{1}$ It is unclear whether the establishment of the "broader impacts" criterion led to any changes in what sorts of archaeological research were funded, as the Archaeology and Anthropology Program

1 In the United States, Archaeology is taught as one of four sub-fields of Anthropology, so the Cultural Anthropology and Archaeology funding programs are often considered together in studies of National Science Foundation funding. 
Officers have consistently stated that the purpose of the funds is to fund "basic research" which directly studies the material remains of the past (e.g. Brush et al. 1981:11).

In 2016, the Wenner-Gren Foundation, which disburses over three million US dollars per year for anthropological and archaeological research funding (Goldstein et al. 2018:4), took visible steps to promote what they call "public engagement with anthropology as a research field" (Lindee and Radin 2016:S294). At that time, they established a publication and grant meant to improve public understanding of anthropology. Each of these is a significant, but measured, step toward acceptance of public outreach as a rigorously pursued part of anthropology in the US. The Engaged Anthropology Grant is described as dissemination support for those who have already been funded by Wenner-Gren and have completed their research (Wenner-Gren Foundation 2018a). Grantees are required to provide a 500-1000 word report at the end of the grant period which is posted on the Wenner-Gren Engaged Anthropology Blog, but no assessment of outcomes is required. Their digital publication, Sapiens, similarly supports the institution's focus on public understanding as well as their long-standing goal to "develop a world community of anthropologists" (WennerGren Foundation 2018b) by carefully recruiting anthropologists to write articles for public consumption and employing a professional editorial process in the style of a journalistic magazine (Wenner-Gren Foundation 2018c). The Wenner-Gren Foundation has dedicated funds and reviewers to assessing principled public outreach efforts, and this makes them stand out among the high-dollar funders of American archaeology. It is unclear, however, to what extent they are interested in implementing assessment of outreach activities beyond the peer-review processes they already employ.

Pressuring funding organizations to reflect research-based best practice - such as routine evaluation of public archaeology activities - has worked before in the USA. According to Brenneis' study of the NSF, for example, the overhaul of the application in 1995 took place when professionals voiced concerns about the fairness of the review process while simultaneously the federal political climate favored reducing financial commitment to the NSF (Brenneis 2009, 243-244). The motivations behind the 1995 NSF 
application changes came from above (federal politics) as well as below (specific tensions between applicants and review committees). In 2018, public accountability is becoming an imperative in science funding worldwide, and it would not be surprising to see politics and scholarly concerns once again converge in a revision of the NSF application guidelines to require evaluation of a project's public impact. For private funding institutions like the WennerGren Foundation, it is less clear what sorts of changes might result from such feedback, but their recent move toward supporting outreach could signal willingness to further integrate best practices of assessment as a component of their funding guidelines.

While institutions have moved slowly on the issue of public archaeology evaluation, it has been a frequent topic of scholarly activities at national conferences and workshops since the mid2000s (Gibb and McDavid 2008; Jeppson 2003, 2004; Jeppson and Brauer 2008; Malloy et al. 2009; Matthews et al. 2010, 2012). Authors of these foundational works explored what assessment could accomplish intellectually and presented case studies in evaluating one's own outreach, usually woven together into a single contribution. Subsequent authors have often described how specific assessment tools have yielded valuable insights for their own public archaeology efforts (Ellenberger and Gidusko 2018; King 2016), but a few have focused broadly on what widespread assessment would mean for the discipline (Ellenberger and Richardson 2015; Gould 2015, 2016; Pageau 2015). We see this as evidence that both theory and method in public archaeology are developing rapidly as they are more widely accepted as important. While public archaeology practitioners appear to be starting to develop norms for evaluation amongst themselves, we see little evidence that institutions which represent, fund, employ, or publish American archaeologists have adopted frameworks for evaluating outreach.

\section{UK}

The biggest funding source for public facing archaeology projects is the government-managed Heritage Lottery Fund (HLF), followed by local authorities and local charities, UK Higher Education, and developer-led archaeology companies, although 
a large percentage (74.6 per cent) of volunteer projects fund themselves (Hedge and Nash 2016, 55). There has also been a steady growth in the number of crowd-funded projects in the UK in recent years (Bonacchi et al. 2015, 4).

It has been estimated that around 90 per cent of all archaeological work in the UK from 1990-2011 took place as part of the development and planning process, rather than in formal academic contexts (Fulford 2011, 33). For the UK, where private commercial archaeology companies undertake the majority of archaeological works within these development-driven contexts, the completion of archaeological mitigation may be the only measure of success, even if public outreach takes place during the programme of work. Developer-led archaeology organisations often publicize their outreach work through various media, for example, Museum of London Archaeology (MOLA 2018) has undertaken extensive community archaeology projects in Greater London and beyond and has a robust outreach and community engagement strategy and reporting mechanisms. However, in most archaeological companies, there are few indicators of the types of evaluation that have taken place, if at all, unless the projects involved received external funding - from the Heritage Lottery Fund (HLF) for example. This is a missed opportunity for shared learning and improvement of project outcomes, despite the challenges of a pressured commercial archaeology environment.

The HLF is subject to state policy control, and the organization reports to Parliament through the department where 'decisions about individual applications and policies are entirely independent of the Government' (HLF 2018a). All funded projects must undertake a programme of evaluation (HLF 2018b). The HLF provides a detailed guide to evaluation good practice, which makes clear recommendations for measuring impact using qualitative and quantitative evidence. The guidance is clear that achievement indicators "determine the relevance and fulfillment of objectives, efficiency, effectiveness, impact and sustainability" (Heritage Lottery Fund 2016b, 3).

Unfortunately, the full range of HLF evaluation reports are not publicly accessible (Claire Butler-Harrison, HLF, pers comm.), and no summaries of feedback or evaluation methodology are 
currently available on the central HLF website, although individual projects may publish their final formal evaluation summaries on their own websites (for example: Jones et al 2015: SCAPE 2017).

In the UK, non-professional, community or 'amateur' participation in archaeology accounts for a relatively small percentage of the amount of archaeological work undertaken each year, although participation in these groups and activities is wellsupported. Research by Historic England suggests that, between 2010-2015, the community archaeology sector had undertaken 12,000 projects (Hedge and Nash 2016, 10). In 2010 the Council for British Archaeology (CBA) recorded over 215,000 people in the UK who are active in heritage, history or archaeology volunteer groups (Thomas 2010, 12). A wide variety of smaller, often local, charitable funding sources for heritage and archaeology exist throughout the UK, although most of these smaller funding streams do not have rigorous guidance for evaluating success (or failure) and their expectations for project outcomes, and projects that are self-funded by participants and community groups may not be evaluated at all. For example, the CBA manages one funding stream for community archaeology, the Mick Aston Archaeology Fund (Council for British Archaeology 2016), which asks for an interim and final project report but no form of evaluation.

Funding for public and community archaeology that is undertaken with UK Higher Education organisations is often part of the work of UK Research and Innovation, which is a strategic partnership of the former UK Research Councils. This body aims to work "in partnership with universities, research organisations, businesses, charities, and government to create the best possible environment for research and innovation to flourish" (UK Research and Innovation 2018). Funding and evaluation of Higher Educationfunded archaeology projects have been affected by the UK impact agenda in higher education and the shift to metrical analysis of knowledge exchange and public engagement which is a wider topic beyond the scope of this paper (James 2018). However, overall, most UK based university archaeology projects do not at present share easily accessible evaluation summaries or reports, with a few notable exceptions, such as the University of Salford (Murphy 2015: Nevell 2013: 2015). 
As Gould $(2016,2)$ points out, case studies are not necessarily generalizable, nor applicable beyond supplying anecdote. The research for this article included a search for evaluation reports from a wide variety of archaeological contexts in the sectors outlined above. This proved difficult if not impossible to do with any comparative meaning, and highlighted some of the challenges of methodological approaches to evaluation and best practice. In the context of the UK, few community-facing project evaluation reports are routinely available in the public domain; those from non-HLF commercial archaeology public archaeology projects are extremely rare. Locating any of these reports in the aftermath of short term project work depends on a number of factors: funding for evaluation to take place; archival standards and practice in the individual project; project websites being maintained and digital reports and information remaining stable; knowledgeable staff being retained after projects end if no online copies of evaluation reports are available; and evaluation reports being confirmed as public documents, rather than reports for funders, trustees, or organisational management only. As Gould (2016: 8) outlines, the HLF has only analyzed the first 100 project reports submitted under its programme (Boyd and Stafford 2013) and the analysis of these is revelatory. Eight projects did not submit an evaluation report, 16 per cent were rated 'very good' or 'good' and 22 per cent were considered to be 'poor'. Practices are, of course, locally driven but this diversity of availability and quality supports the urgent need for a comprehensive synthesis of existing material, to shape evaluation best practice and impact assessment in the future.

\section{Digital Public Archaeology}

Exploiting the affordances of digital technologies in order to encourage participation in public archaeology is an increasingly popular activity within the discipline (Bollwerk 2015; Richardson 2013). The practices of archaeological communication and coproduction within a wholly digital environment can offer new perspectives on public archaeology practice, and these projects are potentially less expensive and easier to manage than 'reallife' projects. In the UK, the HLF provides guidelines for its grant recipients on how to undertake some basic forms of evaluation 
for this type of public engagement, and as many archaeological projects are extending their use of digital media, the potential benefits of evaluation are clear (HLF 2018c). Since the use of this media has an impact on staff time and budget, gathering data on the use and interactions of these platforms are a necessary part of a strategic approach to digital public engagement. Organisations undertaking this form of engagement can use evaluation to better understand user behaviour and user experience within their digital environments. This type of pre-and post project evaluation can help to establish how easily people can find and interact with the information provided, and ultimately learn how to improve future communications and information provision in the landscape of digital technologies. There have been a number of developments of guidance for approaches to the evaluation of the use of these platforms on an individual basis in the culture and museums sector, especially in the UK. For example, Culture 24's "Let's Get Real" project provides extensive guidelines for digital projects in cultural heritage, including how to understand user experiences and evaluating digital outputs (Culture 24 2018). King's College's "Balanced Value Impact Model" 'draws evidence from a wide range of sources to provide a compelling account of the means of measuring the impact of digital resources and using evidence to advocate how change benefits people' (Tanner 2018). Formal evaluations of digital project work in archaeology often measure outcomes and impact through simple assessments of the numbers of attendees, basic demographic data, the quantity of website 'hits', Twitter followers, Facebook page 'likes', or through a selection of participant comments about their enjoyment of activities, made online or offline (Richardson 2014, 153). No analysis of the extent to which digital projects have been collectively successful in terms of encouraging public participation and extending opportunities promised to 'democratize archaeology' has taken place to date. This data would seem to be vital to evaluate the success thus far of the participatory turn in digital archaeology. Meta-analyses of the wider impact of these digital participatory projects are an area ripe for further research in the field of digital public archaeology. 


\section{The Evaluation Imperative}

The key to successful project outcomes may be to include community consultation and partnership into project design itself, but this is not an easy undertaking, and the potential for participatory initiatives to "maintain, rather than upend, existing power structures through the control of acceptable forms of, and locations for, participation" must be acknowledged (Fredheim 2018, 625). There are concerns within the discipline that these types of collaborations could lead to exploitation of volunteers (Fredheim 2018; Perry \& Beale 2015) or to less academically rigorous archaeological projects with vague aims which are more apt to be misinterpreted by those outside the profession (King 2012; Nevell 2013: Simon 2011). While there may be some degree of flexibility afforded by the current lack of institutional structure for public archaeology evaluation, the benefits of existing institutions committing to rigorous and reflexive public archaeology in their codes and institutional mission statements would empower rather than hamper practitioners. However, a critical eye to these issues is vital. It is possible that highly prescriptive evaluation guidelines aligned to institutional agendas for participation could be exploitative, or overlook, silence or other traditionally underrepresented voices in the field, and create structural boundaries between Western practitioners and publics, and 'others' (Atalay 2012: 252-5). In light of these concerns about how to further the usefulness of evaluation in public archaeology, a brief examination of some of the assumptions that professional archaeologists make about the meaning of participation and the use of evaluation is useful.

Using UK case studies, Simpson and Williams (2008) and Woolverton (2016) suggest that there are complex reasons why participants in community archaeology may not know about, nor be interested in, active participation in project design. Reasons why people may choose not to engage with project design might include demographic and socio-economic issues such as age, ethnicity, gender, disability, or class. There may be concerns about educational attainment and confidence, or there may be activities and events which exclude those who are not assimilated fully into in the dominant culture (Dawson 2014a; 2014b). Participants may also be restricted by time, family and work responsibilities, or the 
desire for archaeology to be a social activity, a hobby and a form of relaxation (Hart 2009: 155-159).

Professional archaeological organizations are quiet on the matter of evaluation and outcomes of public archaeology in their ethics statements - no organization in the USA or UK explicitly mentions the need to evaluate public projects and share best practice. Whilst this might seem like a small point for consideration within a greater sectorial management framework, where ethics is an oft-neglected subject, this can create a further disjuncture between our professional interests and values, and those of the communities within which we live and work. What we may perceive to be a successful and engaging project may not provide the kinds of outcomes that participants want, unless the project has input from participant communities during the process of project creation and evaluation. Without this, our assessments of project outcomes will not reflect the subjective, and often nuanced and affective, human experience of participation in archaeological work. If the results of project evaluations do not offer avenues for reflexivity and meaningful change, they may not be worth doing. But how can we learn from the vast insights already existing in our colleagues and communities if there is little iterative guidance and very few robust, published case studies to learn from?

\section{What Can We Do?}

Although there are only a handful of publications that specifically address approaches and methods for evaluating public archaeology projects (for example Apaydin 2016; Human 2015; King 2016; Nevell 2015), archaeologists have been undertaking this work in order to improve their ongoing outreach activities for many years, but these are much less frequently published as formal case studies in scholarly journals. Several dissertations (McDavid 2002; Morgan 2012; Richardson 2014; Stottman 2016) and conference presentations (Gibb and McDavid 2008; Gidusko 2017; Jeppson 2003, 2004, 2011, 2012; Jeppson and Brauer 2008; Malloy et al. 2009; McDavid 2011) have explored evaluation in more depth, although these have not yet been the focus of subsequent journal articles and these may not be universally available in the public realm. 
Scholars have discussed public archaeology evaluation significantly more in conference sessions than in published literature, one recent example being the 2016 Society for American Archaeology session where we presented the first version of this paper (Ellenberger 2016). As demonstrated by the enthusiastic response of that audience, there are interested readers for this topic, and this aspect of practice needs to be better represented in published literature, to share experiences and open up formal assessment practices for further debate. We suggest that the following actions would help to support a better understanding of what our participants want from our work, aid us to share and extend our best practices, and support public archaeology professionals to address the needs and values of the communities in which we work.

\section{Action 1: Better Define Our Goals for Public Engagement}

We must first clearly and honestly define our epistemological, ethical, political, and practical goals if we wish to develop further in our practice. Are we vigilant to the possibility that we may simply reflect, in the methodologies of our work and our evaluations, the types of markers for success that our funders seek, corresponding to 'contemporary official representations of cultural value' (Newsinger and Green 2016: 2)? Do we then marginalize not only the desires of the non-professional participants, but also the evaluation aspirations of the practitioners themselves? We need to examine the dominant discussions of the meaning and method of evaluation with as much attention as we have with 'participation in practice' - since the practice of public archaeology does not begin at the trowel's edge and finish once the last archival box has been packed and we have all gone home.

Guilfoyle and Hogg (2015: 111, also Figure 1) have created a useful intent-based framework with which to classify dimensions of community-based projects, laying the groundwork for comparing public archaeology projects systematically. 
80 - K. ELLENBERGER \& L.-J. RICHARDSON - Reflecting on evaluation...

TABLE 2. Attributes of Community Engagement.

\begin{tabular}{|c|c|}
\hline Attribute & Description \\
\hline Degree of Community Support & What was the level of community support for the project? \\
\hline Degree of Community Control & $\begin{array}{l}\text { Was the community in control of designing the project goals/outcomes? Was the community in } \\
\text { control of designing the project process/outcomes? }\end{array}$ \\
\hline $\begin{array}{l}\text { Degree of Community } \\
\text { Involvement }\end{array}$ & $\begin{array}{l}\text { What was the level of personal participation by community members? What percentage of the } \\
\text { community was aware of the project? }\end{array}$ \\
\hline Degree of Information Flow & Was there open communication and dialogue between the archaeologists and the community? \\
\hline $\begin{array}{l}\text { Degree of Community Needs } \\
\text { Met/ Archaeologist Needs Met }\end{array}$ & Were the needs of the community met? Were the needs of the archaeologists met? \\
\hline
\end{tabular}

Figure 1. Guilfoyle and Hogg's (2015: 111) proposed framework for the characterization of community engagement in archaeological projects. Used with permission from Society for American Archaeology, Copyright 2015.

Another useful framework is Arnstein's (1969) ladder of citizen participation (Cornwall 2008: 270). Her model defines participation through numerous practices, which include: taking part in consultations; deciding how to share information; understanding how to set policies, goals and research frameworks; undertaking programmes and activities; and distributing community benefits and resources. The spectrum of community participation is 'defined by a shift from control by authorities to control by the people or citizens' (Cornwall 2008: 271), although the model, and other similar typologies (White 1996) suggest that the scale of participation ranges from genuine to manipulative and rhetorical. With these frameworks in mind, we should ensure we (and our audiences and participants) have clarity from the outset of our projects exactly what our collective goals are and what everyone wants from their participatory experiences.

\section{Action 2: Share Best Practice}

We need to be able to identify good working practices in community and public archaeology, be aware of good practice within evaluation, and understand how we can incorporate similar activities within our own projects. Measuring impact and outcomes only from community archaeology projects may not provide the types of nuanced information that can inform our future collaborations in any meaningful way. Critiques of participatory 
practice from other disciplines can help us reflect on other ways of understanding the value (or lack of value) placed on public archaeology and find examples of effective evaluation strategies. Evaluation practice in participatory research, visitor studies, and community engagement all provide examples that we could use and adapt (Johanson 2013). Literature under the label of 'heritage work' provides useful examples (Smith 2006) as well as museum studies (Diamond et al. 2009; University of Leicester 2016) and historic site management (for example: Cameron and Gatewood 2000; Markwell et al. 1997).

\section{Action 3: Evaluate with Purpose}

We need to be clear and critical about why we are undertaking project evaluations, and what we want to do with the results. Often, formal evaluation reports in the public realm steer clear of reporting problems and difficult situations, or downplay and ignore any areas where impact has not been felt and needs have not been met. Are we afraid of sharing failure and projects that did not turn out as we expected? Do neoliberal agendas drive these fears because of a pressured financial environment? If we are afraid of failure, then we cannot improve our projects (Graham 2016), or respond to the changing needs and abilities of our stakeholders and partners.

\section{Action 4: Lobby Archaeological Professional Bodies}

Within professional organizations in the USA and Europe (European Association of Archaeologists 2013; Society for American Archaeology 2016), public archaeology interest groups have developed, and facilitated greater collaboration among practitioners. These organizations have the broad reach and infrastructure to support scholarly exchange among public archaeology practitioners, and many have hosted professional meetings that have become central to scholarly exchange between public archaeologists. While it must be recognized that attendance at these events has a high financial cost for registration and participation, which may exclude potential speakers and attendees, we have the opportunity to 
lobby these organizations to put further effort into writing ethical and professional guidelines on public archaeology, and to require reflexive evaluation for public archaeology projects.

\section{Conclusion}

This paper has demonstrated that formal evaluation practice in archaeology is an under-researched and under-valued area of scholarly consideration. Archaeology projects can give voice to communities involved in heritage engagement, but 'there are dangers here of tokenistic work being undertaken to meet institutionally prescribed targets' when government policy filters to the policy aims (and financial capabilities) of heritage organizations, funding bodies and universities (Jackson et al. 2014: 82).

There is a growing need to understand these issues both as part of the dominant cultural value debate of the neoliberal austerity agenda (Jeppson 2012a), and as an opportunity for a progressive development of deeper and broader public participation in archaeological work. Assessment and evaluation may not be uppermost in the minds of archaeologists designing communitybased projects, but this call for greater critical discussion of the outcomes of community archaeology is not naive and misplaced idealism. In the prevailing atmosphere of political instrumentalization of culture and economic austerity, it is all too easy to reduce archaeology to a vehicle for rhetorical nods to issues of social cohesion and well-being, and for the emphasis to be placed on assessments of its economic value to wider society.

Moving beyond the traditional interpretations of 'top-down' or 'bottom-up' public archaeology projects and into an understanding of the relationship between participatory process and satisfactory outcome, is a challenge for public archaeology evaluation. Archaeologists working in both public and privately funded arenas need to be able to demonstrate the impact, credibility and value of their work, but must also recognize the potential for sustainable change and transformation presented by a greater understanding of the social and educational needs and aspirations of our audiences before, during and after our work alongside them. There needs to 
be opportunity to include these concerns in any formal evaluation processes. As Gould (2016: 4) notes, 'only a sound methodology can generate the sound data necessary to identify such practices'. The action points outlined in this article offer some ideas for approaches to formal evaluation with which to shape projects, and to further include stakeholders, influence policy and begin to challenge 'the emerging norms of austerity and neoliberal capitalism' (Newsinger and Green 2016: 2).

\section{Bibliography}

Apaydin, Veysel (forthcoming). The Presentation of the Past: Pitfalls and Potentials- Education and Archaeology in Turkey. In J.H. Jameson \& A. Castillo Mena (eds), Interpreting the Past: Participatory approaches to enhancing public sensitivity and understanding.

Arnstein, Sherry. R. 1969. A ladder of citizen participation. Journal of the American Institute of Planners 35 (4): 216-224.

Atalay, Sonya. 2006. Indigenous Archaeology as Decolonizing Practice. American Indian Quarterly 30 (3): 280-310. doi: 10.1353/aiq.2006.0015.

- 2007. Global Application of Indigenous Archaeology: Community Based Participatory Research in Turkey. Archaeologies 3: 24970. DOI:10.1007/s11759-007-9026-8.

- 2012. Community-based Archaeology: Research With, By, and for Indigenous and Local Communities. Berkeley, University of California Press.

Atalay, Sonya, and Lee Rains Clauss, Randall H. McGuire, John R. Welch. 2014. 'Transforming Archaeology.' In Sonya Atalay, Lee Rains Clauss, Randall. H. McGuire \& John R. Welch (eds.), Transforming Archaeology: Activist Practices and Prospects. Walnut Creek, CA, Left Coast Press, 7-28.

Baram, Uzi. 2011. Community Organizing in Public Archaeology: Coalitions for the Preservation of a Hidden History in Florida. Present Pasts 3 (1): 12-18. DOI:10.5334/pp.40. 
84 - K. ELLENBERGER \& L.-J. RICHARDSON - Reflecting on evaluation...

Belfiore, Eleonora. 2015. "Impact", "value" and "bad economics": Making sense of the problem of value in the arts and humanities.' Arts and Humanities in Higher Education 14(1):95-110.

Bollwerk, Elizabeth. 2015. Co-Creation's Role in Digital Public Archaeology. Advances in Archaeological Practice. 3(3): 223234.

Bonacchi, Chiara, ed. 2012. Archaeology and the Digital: Towards Strategies of Engagement. London, Archetype.

Bonacchi, Chiara, and Daniel Pett, Andrew Bevan, Adi KeinanSchoonbaert. 2015. Experiments in Crowd-funding Community Archaeology. Journal of Community Archaeology \& Heritage 2(3): 184-98.

Boyd, N. \& Stafford, S. 2013. Heritage Grants Programme Evaluation and Outcomes Review. London, Heritage Lottery Fund.

Brenneis, Don. 2009. Anthropology in and of the academy: globalization, assessment and our field's future. Social Anthropology 17(3): 261-275.

Brush, Stephen B. and Mary W. Greene, John E. Yellen. 1981. Anthropology at NSF - Current Status. Anthropology News 22(7): 1-11.

Cameron, Catherine M., and John B. Gatewood. 2000. Excursions into the Un-Remembered Past: What People Want from Visits to Historical Sites. The Public Historian 22: 107-127.

Clarke, John. 2013. In Search of Ordinary People: The Problematic Politics of Popular Participation. Communication, Culture \& Critique 6 (2): 208-226.

Copeland, Tim. 2004. Presenting Archaeology to the Public: Constructing insights on Site. In Nick Merriman (ed.), Public Archaeology. London, Routledge, 132-144.

Cornwall, Andrea. 2008. Unpacking "Participation": Models, Meanings and Practices. Community Development Journal 43(3): 269-83. 
Council for British Archaeology. 2016. Mick Aston Archaeology Fund. Retrieved on 12 June 2016 from WWW [http://new. archaeologyuk.org/mick-aston-archaeology-fund]

Cullen, Tracey. 1995. Women in Archaeology. Antiquity 69 266): 1042-1045.

Culture 24. 2018. Our Research Reports. Retrieved on 25 September 2018 from WWW [https://weareculture24.org.uk/ our-research-reports/]

Dawson, Emily. 2014a. Reframing social exclusion from science communication: Moving away from "barriers" towards a more complex perspective. Journal of Science Communication 13(1): $1-5$.

Dawson, Emily. 2014b. 'Not Designed for Us': How Science Museums and Science Centers Socially Exclude Low-Income, Minority Ethnic Groups. Science Education 98(6): 981-1008.

Diamond, Judy, Jessica J. Luke, and David H. Uttal. 2009. Practical Evaluation Guide: Tool for Museums and Other Informal Educational Settings. Lanham, MD, AltaMira.

Ellenberger, Katharine (organizer). 2016. Assessing Outcomes in Public Archaeology: Imperatives, Perils, and Frameworks. Session at the Society for American Archaeology Annual Meeting. Orlando, FL.

Ellenberger, Katharine and Kevin Gidusko (organizers). 2018. Motivation and Community in Public Archaeology Evaluation. Symposium at the Annual Meetings of the Society for Historical Archaeology, New Orleans, LA.

Ellenberger, Katharine and Lorna-Jane Richardson. 2016. "Satisfying and Reflecting on the Urge to Evaluate in Public Archaeology." Presentation at the Society for American Archaeology Annual Meeting. Orlando, FL.

European Association of Archaeologists. 2016. "EAA Committees and Working Parties 2016." E-A-A.org. Accessed June 13, 2016. [http://e-a-a.org/working groups.htm] 
86 - K. ELLENBERGER \& L.-J. RICHARDSON - Reflecting on evaluation...

Fredheim, L. Harald. 2018. Endagerment-driven heritage volunteering: democratization or 'Changeless Change'. International Journal of Heritage Studies. 24(6): 619-633.

Fulford, Michael. 2011. The impact of commercial archaeology on the UK Heritage. In John Curtis, Michael Fulford, Anthony Harding and Fiona Reynolds, History for the Taking? Perspectives on Material Heritage. London, British Academy, 33-53. Retrieved from the WWW June 12, 2016 [https://www.britac.ac.uk/ policy/History-for-the-taking.cfm]

Gibb, James and Carol McDavid (organizers). 2008. Evaluation of Public Archaeology: Principles, not Protocols. Electronic Session at the Annual Meetings of the Society for Historical Archaeology. Albuquerque, New Mexico.

Gidusko, Kevin (organizer). 2017. "Reevaluating Evaluating Public Archaeology". Panel Discussion at the Annual Meetings of the Society for Historical Archaeology, Fort Worth, TX.

Goldstein, Lynne and Barbara J. Mills, Sarah Herr, Jo Ellen Burkholder, Leslie Aiello, and Christopher Thornton. 2018. "Why Do Fewer Women Than Men Apply for Grants After Their PhDs?" American Antiquity 83(3): 367-386. DOI:10.1017/ aaq.2017.73.

Grey, Clive. 2008. Instrumental policies: causes, consequences, museums and galleries. Cultural Trends 17(4): 209-222.

Graham, Shawn. 2016. "Fail and Loathing in East Lansing: Failing Productively in Digital Archaeology." Lecture, Institute for Digital Archaeology Method and Practice from Michigan State University and National Endowment for the Humanities, East Lansing, MI. August 17, 2016. Retrieved from the WWW [http://shawngraham.github.io/presentations/daifail.html\#/]

Gould, Peter G. 2016. On the Case: Method in Public and Community Archaeology. Public Archaeology 1-18. DOI:10.1080/1465518 7.2016.1199942

Guilfoyle, David R., and Erin A. Hogg. 2015. Towards an EvaluationBased Framework of Collaborative Archaeology. Advances in Archaeological Practice 3(2): 107-23. 
Hart, Siobhan M. 2009. High Stakes: A Poly-Communal Archaeology of the Pocumtuck Fort, Deerfield, Massachusetts. Unpublished PhD thesis, University of Massachusetts Amherst.

Heritage Lottery Fund. 2018a. Our History. Retrieved on 25 September 2018 from the WWW [https://www.hlf.org.uk/ about-us/our-history]

- 2018b. Evaluation Guidance. Retrieved on 25 September 2018 from the WWW [https://www.hlf.org.uk/evaluation-guidance]

- 2018c. Digital technology in heritage projects. Retrieved on 25 September 2018 from the WWW [https://www.hlf.org.uk/ digital-technology-heritage-projects]

Hedge, Rob and Aisling Nash. 2016. Assessing the Value of Community-Generated Historic Environment Research. Historic England. [https://content.historicengland.org.uk/ images-books/publications/assessing-value-of-communitygenerated-historic-environment-research/communitygenerated-historic-environment-research-7178-final-report. $\mathrm{pdf} /]$

Hodder, Ian. 2008. Multivocality and Social Archaeology. In Junko Habu, Clare Fawcett and John M. Matsunaga (eds.), Evaluating Multiple Narratives: Beyond Nationalist, Colonialist, Imperialist Archaeologies. New York, Springer, 196-212.

- 2011. Is a shared past possible? The ethics and practice of archaeology in the twenty-first century. In Katsuyuki Okamura and Akira Matsuda (eds.) New Perspectives in Global Public Archaeology. New York, Springer, 19-28.

Howery, Cherkea. 2013. The effects of the economic crisis on archaeology in Greece. Journal of Eastern Mediterranean Archaeology and Heritage Studies 1(3): 228-233.

Human, Helen. 2015. Democratising world heritage: The policies and practices of community involvement in Turkey. Journal of Social Archaeology 15(2): 160-183.

Jackson, Stella, Rob Lennox, Cath Neal and Steve Roskams. 2014. Engaging Communities in the 'Big Society': What Impact is 
88 - K. ELLENBERGER \& L.-J. RICHARDSON - Reflecting on evaluation...

the Localism Agenda having on Community Archaeology? The Historic Environment 5(1): 74-88.

Jancovich, Leila and Franco Bianchini. 2013. Problematising participation. Cultural Trends. 22(2): 63-66.

James, Toby S. 2018. The higher education impact agenda, scientifc realism and policy change: the case of electoral integrity in Britain. British Politics 13(3): 312-331.

Jeppson, Patrice L. 2003. Learning From the 2003 PEIC K-12 Social Studies Education Event: What can be taken forward from this Public Archaeology experience? Retrieved 29 May 2017 from the WWW [http://www.p-j.net/pjeppson/SHA2003/ LearningPublic.htm]

- 2004. The SAA Public Education Committee. Report on SHA at NCSS: Exhibit Booth \#853 out of 1053. Evaluation of a public outreach activity at the National Council for the Social Studies. Retrieved 29 May 2017 from the WWW [http://www.p-j.net/ pjeppson/NCSS2004/Booth.htm]

- 2011. The Dynamics of Inclusion at 'The Dynamics of Inclusion', a Public Archaeology Workshop Public Event. Archaeologies 7(3): 635-656.

- 2012a. Public Archaeology and the US Culture Wars. In Robin Skeates, Carol McDavid and John Carman (eds.), The Oxford Handbook of Public Archaeology. New York, Oxford University Press, 581-604.

- 2012b Archaeology and the Interpretation of the President's House: Limits and Largesse. Presentation at Annual Meetings of the Society for Historical and Underwater Archaeology. Baltimore, MD.

Jeppson, Patrice L. and Karen Brauer. 2008. Can Evaluation Be More? Principles of evaluation and the relationship between materiality and social existence. Presentation at Annual Meetings of the Society for Historical and Underwater Archaeology. Albuquerque. 
Johanson, Katya. 2013. "Listening to the Audience: Methods for a New Era of Audience Research." In Jennifer Radbourne, Hilary Glow, and Katya Johanson (eds.), The Audience Experience: A critical analysis of audiences in the performing arts. Bristol, Intellect, 159-172.

Jones, S., Hannah Cobb, Melanie Giles, Ken Shone, and Ruth Colton. 2015. Whitworth Park Community Archaeology and History Project: An Evaluation Report for the Heritage Lottery Fund. Retrieved 25 September 2018 from WWW: [https:// www.escholar.manchester.ac.uk/uk-ac-man-scw: 281851]

King, Eleanor (editor). 2016. Special Issue: Designing and Assessing Public Education Programs in Archaeology. Advances in Archaeological Practice 4(4):415-549.

King, Tom. 2012. "Public archaeology is a menace to the public and archaeology." AP: Online Journal in Public Archaeology 2: 5-9.

Lindee, Susan and Joanna Radin. 2016. Patrons of the Human Experience: A History of the Wenner-Gren Foundation for Anthropological Research, 1941-2016. Current Anthropology 57(S14): S218-S301. DOI:10.1086/687926.

Malloy, Maureen and Patrice L. Jeppson, Carol McDavid. 2009. The Ends of "Archaeology for the public". Presentation at American Anthropological Association Annual Conference. Philadelphia.

Markwell, Susan, Marion Bennett, and Neil Ravenscroft. 1997. The Changing Market for Heritage Tourism: A Case Study of Visits to Historic Houses in England. International Journal of Heritage Studies 3(2): 95-108.

Matsuda, Akira., \& Katsuyuki Okamura. 2011. Introduction: New perspectives in global public archaeology. In Akira Matsuda and Katsuyuki Okamura, New Perspectives in Global Public Archaeology. London: Springer, 1-18.

McDavid, Carol. 2011a. Bibliography of Public Archaeology Sources. Archaeologies 7(3): 657-666. 
90 - K. ELLENBERGER \& L.-J. RICHARDSON - Reflecting on evaluation...

- 2011b. Considering the Longue Durée of Public Archaeology. Presentation in, M. Jay Stottman (organizer), Archaeologists as Activists: Moving Forward on a Practice of Activist Archaeology. Annual Meetings of the Society for Historical Archaeology, Austin, Texas.

McGuire, Randall H. 2008. Archaeology as Political Action. Berkeley, University of California Press.

Mickel, Allison and Alex R. Knodell. 2015. We wanted to take real information: public engagement and regional survey at Petra, Jordan. World Archaeology 47(2): 239-260.

MOLA. 2018. Research and engagement. Retrieved on 25 September 2018 from WWW [https://www.mola.org.uk/ research-engagement/community-engagement]

Murphy, P., 2015. Building a Head of Steam: Digging Moston. In: Nevell, M. and Redhead, N., eds. Archaeology for All. Community Archaeology in the Early 21st Century: Participation, Practice and Impact. Salford: Salford University, 89-94.

Neal, C. 2015a. Heritage and participation, In E. Waterton \& S. Watson (Eds) Handbook of contemporary heritage research, 346-365. Basingstoke: Palgrave McMillan.

Neal, C. 2015b. Know your place? Evaluating the therapeutic benefits of engagement with historic landscapes. Cultural Trends. 24(2):133-142. DOI: 10.1080/09548963.2015.1031479

Nevell, Mike. 2013. Archaeology for all: Managing expectation and Learning from the Past for the Future- The Dig Manchester Community Archaeology Experience. In: Dalglish, C., ed. Archaeology, the public and the recent past. Boydell Press, 65-76.

Nevell, Mike., 2015. The Dig Manchester Project, 2005-2209: Redefining Community Archaeology? In: Nevell, Mike. and Redhead, N., eds. Archaeology for All. Community Archaeology in the Early 21st century: Participation, Practice and Impact. Salford: Centre for Applied Archaeology, University of Salford, 35-46. 
Newsinger, Jack and William Green. 2016. The infrapolitics of cultural value: cultural policy, evaluation and the marginalization of practitioner perspectives. Journal of Cultural Economy. 2016: 1-14. DOI: $10.1080 / 17530350.2016 .1141791$

Pageau, Hanna Marie. 2016. Archaeology and Experiential Learning: The Unique Impact of Learning Experientially for the Field Sciences. Presentation at the Society for American Archaeology Annual Meeting. Orlando, FL.

Plattner, Stuart, Gary Aronson and Benjamin Abellera. 1993. Recent Trends in Funding Anthropological Research at the National Science Foundation. Human Organization 52(1): 110-114.

Plattner, Stuart, Linda Hamilton and Marilyn Madden. 1987. The Funding of Research in Social-Cultural Anthropology at the National Science Foundation. American Anthropologist 89: 853-866.

Plattner, Stuart and Christopher McIntyre. 1991. The Funding of Dissertation Research in Anthropology at the National Science Foundation. Human Organization 50: 203-208.

Richardson, Lorna-Jane. 2013. A Digital Public Archaeology? Papers from the Institute of Archaeology 23(1): 1-12.

Richardson, Lorna-Jane. 2014. Public Archaeology in a Digital Age. Unpublished PhD thesis, University College London. Retrieved 25 September 2018 from WWW [http://discovery.ucl.ac.uk/ id/eprint/1436367]

Richardson, Lorna-Jane. \& Jaime Almanza-Sanchez. 2015. Do You Even Know What Public Archaeology Is? Trends, Theory, Practice, Ethics. World Archaeology 47(2): 194-211.

Roskams, Steve., \& Cath Neal. 2013. Authority and Community: Reflections on archaeological practice at Heslington East, York. The Historic Environment: Policy \& Practice, 4(2): 139155.

Schadla-Hall, Tim. 1999. Editorial: Public archaeology. European Journal of Archaeology 2(2): 147-158. 
92 - K. ELLENBERGER \& L.-J. RICHARDSON - Reflecting on evaluation...

Schadla-Hall, Tim, Gabriel Moshenska and Amara Thornton. 2010. Editorial. Public Archaeology 9(2): 62-63.

SCAPE. 2017. Scotland's Coastal Heritage at Risk Final Evaluation Report. Retrieved 25 September 2018 from WWW [http:// scharp.co.uk/media/medialibrary/2017/09/SCHARP-HLFEVALUATION FINAL web.pdf]

Shanks, Michael and Randall H. McGuire. 1996. The Craft of Archaeology. American Antiquity 61(1): 75-88.

Simon, Nina. 2011. Participatory design and the future of museums. In Bill Adair, Benjamin Filene and Laura Colossi (eds.), Letting Go? Sharing Historical Authority in a User-Generated World. Walnut Creek, Left Coast Press, 18-33.

Simpson, Faye and Howard Williams. 2008. Evaluating community archaeology in the UK. Public Archaeology 7(2): 69-90.

Skeates, Robin, Carol McDavid and John Carman. eds. 2012. The Oxford Handbook of Public Archaeology. Oxford, Oxford University Press.

Silliman, Stephen W. 2008. Collaborating at the Trowel's Edge: Teaching and Learning in Indigenous Archaeology. Tucson, University of Arizona Press.

Smith, Claire, and Hans Martin Wobst. 2005. Indigenous Archaeologies: Decolonizing Theory and Practice. London, Routledge.

Smith, Laurajane. 2004. Archaeological Theory and the Politics of Cultural Heritage. London, Routledge.

- 2006. Uses of Heritage. London, Routledge.

Smith, Laurajane, and Emma Waterton. 2009. Heritage, Communites and Archaeology. London, Duckworth.

Society forAmerican Archaeology. Public Archaeology Interest Group. Retrieved 13 June 2016 from WWW [http://www.saa.org/ formembers/interestGroups/publicarchaeologyinterestgroup/ tabid/156/default.aspx] 
Spector, Janet. 1993. What This Awl Means: Feminist Archaeology at a Wahpeton Dakota Village. St. Paul, Minnesota Historical Society Press.

Tanner, Simon. 2018. The Balanced Value Impact Model. Retrieved 25 September 2018 from WWW [https://www.kdl.kcl.ac.uk/ what-we-do/consultancy/strategic-thinking-and-practice/ balanced-value-impact-model/]

Thomas, Suzie. 2010. Community Archaeology in the UK: Recent Findings. York, Council for British Archaeology.

UK Research and Innovation. 2018. Retrieved 25 September 2018 from WWW [https://www.ukri.org/]

United States Forest Service. Passport In Time's Purpose. Retrieved 13 June 2016 from WWW [http://www.passportintime.com/ pit-s-purpose.html]

United States National Science Foundation. Research Areas. Retrieved 13 June 2016 from WWW [http://www.nsf.gov/ pubs/2007/nsf07046/nsf07046.jsp]

United States National Park Service. Secretary's Standards Qualifications Standards. Retrieved 13 June 2016 from WWW [https://www.nps.gov/history/local-law/arch stnds 9.htm]

University of Leicester. Evidencing the Impact of the Generic Learning Outcomes. Retrieved 13 June 2016 from WWW [http://www2.le.ac.uk/departments/museumstudies/rcmg/ projects/evidencing-the-impact-of-the-generic-learningoutcomes]

Vuyk, Kees. 2010. The arts as an instrument? Notes on the controversy surrounding the value of art. International Journal of Cultural Policy 16(2): 173-183.

Waterton, Emma. 2005. Whose sense of place? Reconciling archaeological perspectives with community values: Cultural landscapes in England. International Journal of Heritage Studies 11(4): 309-325. 
94 - K. ELLENBERGER \& L.-J. RICHARDSON - Reflecting on evaluation...

Watkins, Joe E. 2003. Beyond the Margins: American Indians, First Nations, and Archaeology North America. American Antiquity 68(2): 273-285.

Wenner-Gren Foundation. 2018a. Engaged Anthropology Grant General Criteria of Evaluation. Retrieved 3 August 2018 from WWW [http://www.wennergren.org/programs/engagedanthropology-grant/general-criteria-evaluation-0]

- 2018b. About the Foundation. Retrieved 3 August 2018 from WWW [http://www.wennergren.org/about/about-foundation]

- 2018c. Sapiens: Write for Us. Retrieved 3 August 2018 from WWW [https://www.sapiens.org/write-for-us]

White, Sarah. 1996. 'Depoliticising development: the uses and abuses of participation', Development in Practice, 6(1),6-15

Woolverton, Jemima. 2016. 'Becoming History Ourselves': A Study of Age Demographics in Community Archaeology Societies." Journal of Community Archaeology \& Heritage 3(2): 135-151.

Yellen, John E, Mary W. Greene and Richard T. Louttit. 1980. A Response to "National Science Foundation Funding of Domestic Archaeology in the United States: Where the Money Ain't." American Antiquity 45(1): 180-181. 


\section{BLOG REVIEWS WITHIN VOL 8}

García Raso, D. Playing Prehistory with Far Cry Primal - 7 October

You can read them at:

http://arqueologiapublica.blogspot.com/ - Reviews 


\section{HOW TO CONTRIBUTE}

AP: Online Journal in Public Archaeology welcomes original contributions that match the aims of the journal and have not been previously published anywhere else, or are not on the way to be published elsewhere. Being online and free can be understood as a sign of quality degradation, but this is not a barrier. It is just a way to adapt from the very first moment to the new panorama in research, where the Internet is the main vehicle for transmission, and more specifically in our field, where the prices of journals are unaffordable for any researcher that is not linked to a research institution. We try to give the widest publicity to the journal, to make it Public.

Having made this clear, the papers can be sent in different ways:

-Mail:

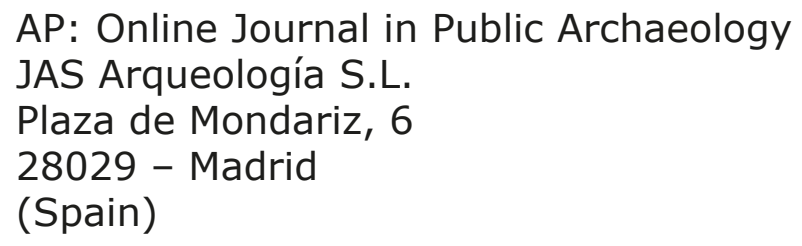

-Email:

jasarqueologia@gmail.com

-Filemail.com:

Filemail.com (www.filemail.com) is a free tool to send large files that exceed the upload limit of a normal email account (Gmail, for example, permits up to $25 \mathrm{Mb}$ ). It is a useful way of sending, for example, large images. In this case, please contact us via email first in case we are not able to get them immediately (the link expires in three days).

Of course, any other similar application can be also accepted, like Wetransfer or Dropbox. 
STYLE

Length:

Full articles - We will only accept papers of less than 10.000 words (including notes and references) with a maximum of 10 figures (tables are counted as text).

Work reports - We will only accept papers of less than 5.000 words (including notes and references) with a maximum of 5 figures (tables are counted as text).

Reviews - We will only accept papers of less than 2.000 words (including notes and references) with 1 figure, that in case of book reviews will be the cover. In other events (conferences, film festivals...), the figure must clearly reflect the event.

Presentation:

To follow the indications of Public Archaeology (www.maney. co.uk/journals/pua), and aiming to standardize the procedures from our side, all material should follow the MHRA Style Guide, which can be freely downloaded from:

http://www.mhra.org.uk/Publications/Books/StyleGuide/index. html

Figures:

The quality of figures should be good enough to be clear in a PDF file. There will not be any weird rule for the submission of the files. Just submit the figures in any readable format (able to be edited in Adobe Photoshop ( $)$ ). Every camera, software of scanner can make good quality images, so just submit originals. If any figure is subject to copyright it will be essential to attach a written permission from the holder of the rights. To avoid any inconvenience, we encourage the publication of self-owned images. In any case, the author will be responsible for any violation of copyright issues.

Notes and references:

It is preferable to avoid footnotes in the text, just quote or explain in brackets. 
For references use Harvard style (Author 2010: 322) followed by a final bibliography. For example: 'according to Author (2010: 123) Public Archaeology can be...' or 'it has been pointed out (Author 2010: 13) that...' etc.

Multiple citations should be in alphabetical order and separated by a semi-colon, (Author et al., 1990; Creator and Author 2003; Producer 1982).

Where an author has several publications from the same year, distinguish them with 'lower-case' letters (Author 2010a, 2010b). Do not use ibid.

In the final bibliography follow the system below:

Thesis

Castillo Mena, A. 2003. La Gestión del Patrimonio Arqueológico en la Comunidad de Madrid. Unpublished PhD thesis, Universidad Complutense de Madrid.

Journal article

Matsuda, A. 2004. The concept of "the Public" and the aims of Public Archaeology. Papers from the Institute of Archaeology 15, 66-76.

Book

Demoule, J. P. 2007. L'archéologie préventive dans le monde. Apports de l'archéologie preventive a la connaisance du passé. Paris, La Décuverte.

Edited book

Durbin, G. (ed.) 1996. Developing Museum Exhibitions for Livelong Learning. London, GEM.

Section in book

McEwan, C., Silva, M. I. and Hudson, Ch. 2006. Using the past to forge the future: the genesis of the community site museum at Aguablanca, Ecuador. In H. Silverman (ed.), Archaeological site museums in Latin America. Gainesville, University of Florida Press, 187-216. 
Internet reference

United Nations 1992, Agenda 21. Retrieved on 29 January 2010 from WWW [http://www.un.org/esa/dsd/agenda21/res_ agenda21_00.shtml]

(As it is an online publication, all the quotes referring to an Internet address should be active links).

In the case of any other kind of reference not mentioned here, please contact the editor.

Once the article has been received:

The process for the acceptance of papers will be easy and fast. Once the article has reached the editor, the decision will be taken in less than 48 hours. Papers rejected from the editor will not be considered again unless they undertake major changes. Correspondence will not be continued for those papers. If the paper is pre-accepted by the editor, it will be peer-reviewed by two different experts in the common blind process. After that, the author will be given feedback and advice in order to go over the article, which will be corrected again to check if it meets the requirements of the reviewers. Once this process has finished, the article will be edited as it will appear on the journal and returned to the author for a final check (only spelling mistakes or other details, not changes on the text). The commitment of the journal is to be able to complete the whole process in less than two months.

Work reports and reviews will not need to pass the peerreview process, but will be commented by the editor.

We will be publishing one volume per year (first trimester) and although we are willing to receive papers the whole year, full articles for next-year's volume should be sent before October in order to complete the process with time.

If you have any queries, please do not hesitate to contact the editor at: jasarqueologia@gmail.com 


\section{LIST OF DONORS}

We want to thank all the people that is helping to maintain this journal. Especially those that chose to use one of the procedures in the donations page. Every little help is welcome to continue with this project, and we expect to increase this list year by year with your help.

Thank you very much:

Vicky Papagiannopoulou

Giannis Papagiannopoulos

Alipio Sánchez

Ma Ángeles Sánchez

José Ma Almansa

Mayca Rojo

Gaëlle Cerruti

Carlos Tejerizo

Jacob Hilton

Patrice L. Jeppson

Gemma Cardona

Ioannis Poulios

Howard Williams

Klaudia Karpinska 


\section{AP: Ontine Journat in Public Archaeology}

Editors:

Jaime Almansa Sánchez \& Elena Papagiannopoulou

Email: almansasanchez@gmail.com

Assistant editors:

Amanda Erickson Harvey

Reviews editor:

Alexandra Ion

Assistant production editor:

Alejandra Galmés Alba

Edited by:

JAS Arqueología S.L.U.

Website: www.jasarqueologia.es

Email: jasarqueologia@gmail.com

Address: Plaza de Mondariz, 6, 28029 - Madrid (Spain)

$--$

Cover Image: Cacaclismo (Jaime Delgado)

Copyleft 2018 JAS Arqueología S.L.U. (edition) \& Authors (content)

ISSN: 2171-6315

AP Journal is a peer-reviewed journal devoted exclusively to Public Archaeology. It is freely distributed online on the Website:

www.arqueologiapublica.es

You can also follow us on:

Blogger:

= http://arqueologiapublica.blogspot.com/

Twitter:

http://twitter.com/APjournal

Facebook:

http://www.facebook.com/APJournal 